\title{
MicroRNA-126 enhances the sensitivity of osteosarcoma cells to cisplatin and methotrexate
}

\author{
LIANGDONG JIANG $^{1}$, AIYONG HE ${ }^{1}$, XIAOJIE $\mathrm{HE}^{2}$ and CHENG TAO ${ }^{1}$ \\ ${ }^{1}$ Department of Orthopedics; ${ }^{2}$ Children's Medical Center, The Second Xiangya Hospital, \\ Central South University, Changsha, Hunan 410011, P.R. China
}

Received October 21, 2014; Accepted July 16, 2015

DOI: 10.3892/ol.2015.3790

\begin{abstract}
The establishment of novel chemotherapy drugs for osteosarcoma is urgently required, and the mechanisms and effects of cisplatin (DDP) and methotrexate (MTX) in the current treatment of osteosarcoma have not been fully elucidated. The present study aimed to observe the effect of DDP, MTX and rapamycin on osteosarcoma cell proliferation and apoptosis, and to investigate the association between miR-126 and the effects of DDP and MTX in osteosarcoma cells. miR-126-overexpressing and -silencing lentiviral vectors were constructed, and MG63 and U-2 OS osteosarcoma cells were infected. An MTT assay was conducted to detect transfected cell proliferation, and the effects of the chemotherapy drugs on transfected cell apoptosis were detected by flow cytometry. The cell cycle of the transfected cells was analyzed via flow cytometry. As the miR-126-overexpressing and -silencing osteosarcoma cell lines were successfully constructed, it was observed that DDP and MTX inhibited osteosarcoma cell proliferation. With the decreased expression of miR-126, the sensitivity of osteosarcoma cells to DDP and MTX was reduced at the same concentration. The flow cytometry suggested that DDP and MTX could promote the apoptosis of osteosarcoma cells with overexpressed miR-126, whereas they could not significantly impact the apoptosis of the miR-126-silenced osteosarcoma cells. Meanwhile, DDP inhibited the cell cycle of the miR-126-overexpressing osteosarcoma cells. In conclusion, DDP and MTX inhibited the proliferation and promoted the apoptosis of the osteosarcoma cells, and these processes were dependent upon the expression of miR-126.
\end{abstract}

Correspondence to: Dr Cheng Tao, Department of Orthopedics, The Second Xiangya Hospital, Central South University, 139 Middle Renmin Road, Changsha, Hunan 410011, P.R. China E-mail: taocheng201405@163.com

Abbreviations: DDP, cisplatin; RAPA, rapamycin; miR, microRNA; MTX, methotrexate

Key words: microRNA-126, osteosarcoma, DDP, MTX, RAPA

\section{Introduction}

As an important fragment with biological functions, mature microRNA-126 (miRNA/miR-126) is associated with the angiogenesis, proliferation and differentiation of stem cells, as well as the development of various tumors (1-4). Osteosarcoma, the most common primary malignant tumor, has exhibited a high prevalence in the past 20 years, therefore, the establishment of novel chemotherapy drugs for osteosarcoma is urgently required (5-7). Approximately 900 novel cases are diagnosed each year in the USA $(8,9)$. It is estimated that osteosarcoma accounts for $\sim 20 \%$ of bone cancers, the incidence rate of osteosarcoma is $4.6-5.6 \%$ for the range $0-19$ years per year per million persons worldwide (10). Previous studies have demonstrated that DDP plus gemcitabine was associated with a significant survival advantage without the addition of substantial toxicity and MTX was proved to improve disease-specific outcomes and reduce collateral damage in patients with rheumatoid arthritis $(11,12)$. Cisplatin (DDP) and methotrexate (MTX) are commonly used as clinical chemotherapy drugs, although their roles and effects in the current treatment of osteosarcoma have not been fully elucidated $(13,14)$. Aberrant activation of the PI3K/Akt/mTOR pathway is observed in numerous types of cancer and is considered to serve a major role in breast cancer cell proliferation and anti-cancer drug resistance (15), Moreover, Akt promotes protein synthesis and cell growth by activating mTOR through effects on the intermediary tuberous sclerosis $1 / 2$ complex (16). In the present study, lentiviral vectors overexpressing and silencing miR-126 were constructed to infect a variety of osteosarcoma cells, so as to observe the sensitivity of miR-126 to the clinical use of DDP and MTX in the treatment of osteosarcoma cells. The study aimed to obtain results supporting the treatment of osteosarcoma by DDP and MTX, thereby enabling the use of personalized treatment programs and further reducing the drug resistance to chemotherapy drugs.

\section{Materials and methods}

Cell culture and dosage. The MG63 and U-2 OS cell lines were purchased from the American Type Culture Collection (Manassas, VA, USA). The cells were cultured in Dulbecco's modified Eagle's medium (Sigma-Aldrich, St Louis, MO, USA) and placed in a $5 \% \mathrm{CO}_{2}$ incubator. When $80 \%$ of cell 
fusion was completed, the cells were digested with $0.25 \%$ trypsin and subcultured in accordance with requirements in different Petri dishes until the cells grew to $70 \%$ confluence. In this experiment, rapamycin (RAPA; $100 \mathrm{~nm})$, DDP $(20 \mu \mathrm{M})$ and MTX $(100 \mu \mathrm{M})$ (Sigma-Aldrich) were selected, and the cells were treated with the drugs for $48 \mathrm{~h}$. Subsequent experiments could then be performed. The study was approved by the ethics committee of the Second Xiangya Hospital (Central South University, Changsha, China).

Construction of lentiviral vectors overexpressing and silencing $m i R-126$. A target gene, chemically synthesized and linearly ligated into the AgeI lentiviral vector, was transformed into competent bacterial cells. Once the first colony was identified by polymerase chain reaction (PCR), the positive clones were sequenced and comparatively analyzed. The total volume of the reaction was $20 \mu \mathrm{l}: 5 \mu \mathrm{l}$ of sense oligonucleotide $(200 \mu \mathrm{mol} / \mathrm{l})$, $5 \mu \mathrm{l}$ of antisense oligonucleotide $(200 \mu \mathrm{mol} / \mathrm{l}), 2 \mu \mathrm{l}$ of $10 \mathrm{X}$ annealing buffer and $8 \mu \mathrm{l}$ of $\mathrm{ddH}_{2} \mathrm{O}$. A proper comparison was made to successfully clone a target plasmid, while purified viruses were measured by ELISA (KHB, Shanghai, China).

Establishing stably-infected osteosarcoma cell lines. The level of miR-126 expression in the two osteosarcoma cell lines, MG-63 and U-2 OS, was detected by quantitative PCR following miR-126-overexpressing and -silencing lentiviral vector infection. Total RNA was isolated from using MirVana TM miRNA Isolation Kit (ABI, Roche, Branchburg, NJ, USA). Then the total RNA was transcribed into cDNA at $16^{\circ} \mathrm{C}$ for $30 \mathrm{~min}, 42^{\circ} \mathrm{C}$ for $30 \mathrm{~min}, 85^{\circ} \mathrm{C}$ for $30 \mathrm{~min}$, and stored at $4^{\circ} \mathrm{C}$. The reverse-transcription for GAPDH were conducted at $45^{\circ} \mathrm{C}$ for $1 \mathrm{~h}$, then $70^{\circ} \mathrm{C}$ for $10 \mathrm{~min}$, and saved at $4^{\circ} \mathrm{C}$. The detection of miR-126 and GAPDH were conducted using the fluorescent dye SYBR Green. The sequences of the primers used for amplification were as follows: miR-126, F 5'-ACACTCCAG CTGGGTCGTACCGTGAGTAAT-3' and R 5'-TGGTGTCGT GGAGGAGTC-3'; GAPDH, F 5'-GAAGGTCGGAGTCAA CGGATT-3' and R 5'-ATGGGTGGAATCATATTGGAA-3'. The PCR reaction for miR-126 were $95^{\circ} \mathrm{C}$ for $5 \mathrm{~min}, 95^{\circ} \mathrm{C}$ for $15 \mathrm{sec}, 60^{\circ} \mathrm{C}$ for $15 \mathrm{sec}$ and a total 40 cycles were performed. GAPDH were conducted under $95^{\circ} \mathrm{C}$ for $5 \mathrm{~min}, 95^{\circ} \mathrm{C}$ for $15 \mathrm{sec}, 60^{\circ} \mathrm{C}$ for $1 \mathrm{~min}$ and total of 50 cycles were performed. Fluorescence signals were collected at $85^{\circ} \mathrm{C}$ and GAPDH was used as an internal reference. After PCR was performed, the mRNA level was calculated by a comparative threshold cycle $(\mathrm{Ct})$ method using the formula $2^{-\Delta \Delta \mathrm{Ct}}$. miR-126 expression in the stably-transfected osteosarcoma cell lines was tested for using immunofluorescence analysis.

MTT analysis of the effects of three different chemotherapy drugs upon transfected cell proliferation. Culture medium containing $10 \%$ calf serum was used to prepare a single cell suspension, and $\sim 10,000$ cells per well were seeded in 96-well plates. The cells were cultured overnight until the cell density increased to $70 \%$. The medium was replaced by $100 \mu \mathrm{l}$ serum-free medium, cultured for $24 \mathrm{~h}$ and then synchronized. In the experiment, the cells were divided into different treatment groups, forming the control, RAPA $(100 \mathrm{nM})$, DDP $(20 \mu \mathrm{M})$ and MTX $(100 \mu \mathrm{M})$ groups. A total of $10 \mu \mathrm{l}$ MTT (5 mg/ml) was added to each well at different times (12,
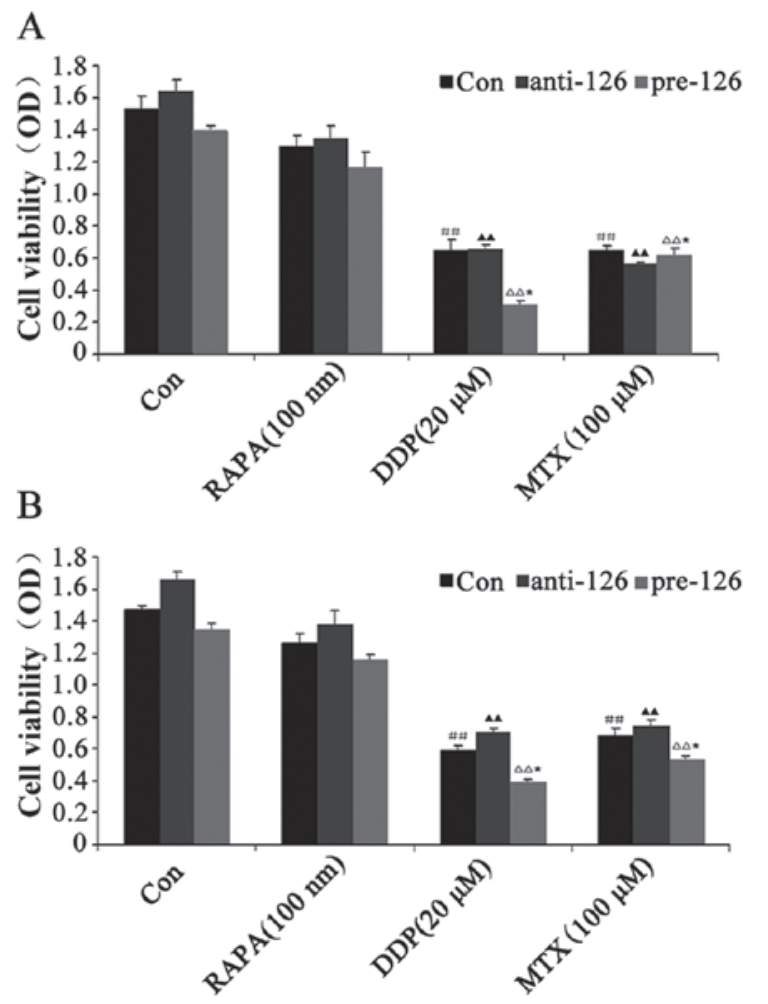

Figure 1. Effect of DDP, MTX and RAPA on osteosarcoma cell proliferation. (A) MG63 osteosarcoma cells were infected with miR-126-overexpressing or -silencing lentiviral vectors. The effect of DDP, MTX and RAPA on osteosarcoma cell proliferation was then observed by MTT. (B) U-2 OS osteosarcoma cells were infected with miR-126-overexpressing or -silencing lentiviral vectors. The effect of DDP, MTX and RAPA on bone tumor cell proliferation was then observed by MTT. ${ }^{\#, \mathbf{\Lambda} \Delta} \mathrm{P}<0.01$ vs. control group; ${ }^{*} \mathrm{P}<0.05$ vs. anti-miR-126 group. DDP, cisplatin; MTX, methotrexate; RAPA, rapamycin; pre-miR-126, osteosarcoma cells infected with miR-126-overexpressing lentiviral vectors; anti-miR-126, osteosarcoma cells infected with miR-126-silencing lentiviral vectors; OD, optical density.

24 and $48 \mathrm{~h}$ ). The cells were incubated for $4 \mathrm{~h}$ and then the culture was terminated. With the culture supernatant in the net absorption hole, $150 \mu \mathrm{l}$ dimethyl sulfoxide was added to each well. Optical density values at a 570 -nm wavelength were measured with an automatic microplate reader (Dynatech MR4000; Dynatec Laboratories, Inc., El Paso, TX, USA).

Flow cytometry to detect the effects of chemotherapeutic drugs on the apoptosis of transfected cells. A total of $2 \mathrm{ml}$ $\left(1 \times 10^{6}\right.$ cells $\left./ \mathrm{ml}\right)$ of cells were seeded in 6-well plates, then treated with $100 \mathrm{nM}$ of RAPA, $20 \mu \mathrm{M}$ of DDP and $100 \mu \mathrm{M}$ of MTX and the culture was stopped after $48 \mathrm{~h}$. Following centrifugation for $5 \mathrm{~min}$ at $800 \mathrm{x}$ g, the cells were collected through sedimentation, while the supernatant was discarded and washed twice with pre-cooled phosphate-buffered saline (PBS). Cold $75 \%$ ethanol was added overnight at a fixed temperature of $4^{\circ} \mathrm{C}$. Following centrifugation at $1,500 \mathrm{x}$ g for $5 \mathrm{~min}$, the supernatant was discarded and the cells were washed with $3 \mathrm{ml}$ of PBS once. In total, $400 \mu \mathrm{l}$ ethidium bromide $(50 \mu \mathrm{g} / \mathrm{ml})$ and $100 \mu \mathrm{l}$ RNase A (100 $\mu \mathrm{g} / \mathrm{ml})$ (Sigma-Aldrich) were added at $4^{\circ} \mathrm{C}$ in the dark for $30 \mathrm{~min}$. A total of 20,000 cells were counted according to standard procedures through flow cytometry (Becton Dickinson, Franklin Lakes, NJ, USA) and the treatment results were analyzed with ModFit (Verity 

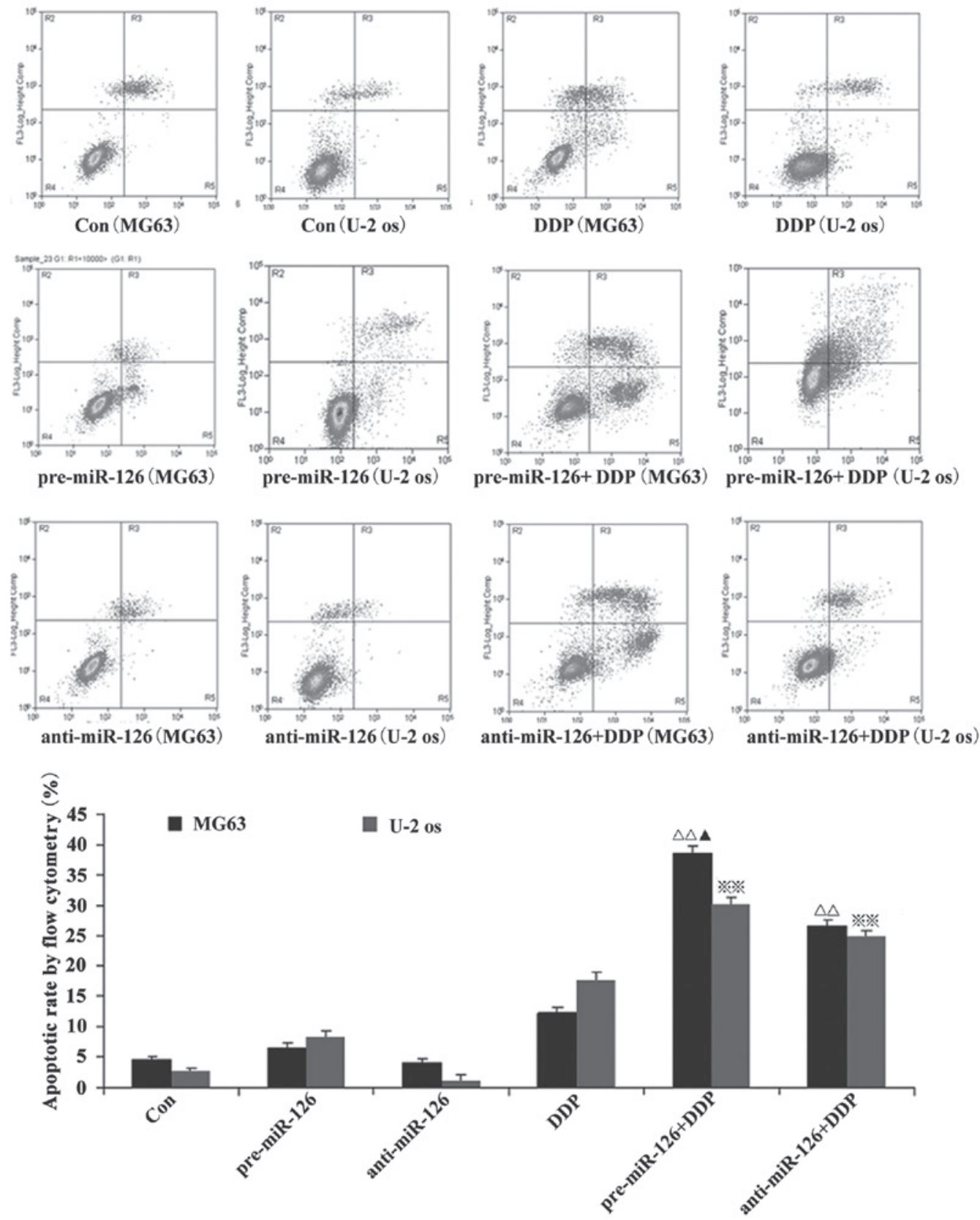

Figure 2. Effect of DDP on osteosarcoma cell apoptosis. Osteosarcoma cells (MG63 and U-2 OS) were infected by miR-126-overexpressing or -silencing lentiviral vectors. The effect of DDP on osteosarcoma cell apoptosis was then observed by flow cytometry. ${ }^{\Delta \Delta, * *} \mathrm{P}<0.01$ vs. control group; ${ }^{\mathbf{\Delta}} \mathrm{P}<0.05$ vs. pre-miR-126 group. DDP, cisplatin; MTX, methotrexate; RAPA, rapamycin; pre-miR-126, osteosarcoma cells infected with miR-126-overexpressing lentiviral vectors; anti-miR-126, osteosarcoma cells infected with miR-126-silencing lentiviral vectors.

Software House, Chula Vista, CA, USA), the DNA analysis software.

Flow cytometry for the detection of the cell cycle in transfected cells. The cells in the logarithmic growth phase were digested and counted. The cell concentration was adjusted to $1 \times 10^{5} / \mathrm{ml}$ and seeded in 6-well plates. Each well was provided with $2 \mathrm{ml}$ cell solution and the cells were cultured in a $5 \% \mathrm{CO}_{2}$ incubator at $37^{\circ} \mathrm{C}$. For the treatment groups, RAPA $(100 \mathrm{~nm})$, DDP $(20 \mu \mathrm{M})$ or MTX $(100 \mu \mathrm{M})$ were then added in the logarithmic growth phase. Meanwhile, a solvent control group was set, with two wells at the same concentration. Once the cell culture plate was cultured in the $5 \% \mathrm{CO}_{2}$ incubator for $48 \mathrm{~h}$, the fluid culture was collected in a centrifuge tube where the cells were digested and collected at $4^{\circ} \mathrm{C}$. The cells were centrifuged at a rate of $1,000 \mathrm{x}$ g for $5 \mathrm{~min}$. The supernatant was discarded and the cells were washed once with ice cold PBS. The cells were collected in a centrifuge tube at $4^{\circ} \mathrm{C}$ and centrifuged at $1,000 \mathrm{x} g$ for $5 \mathrm{~min}$. The supernatant was discarded, while the ice cold PBS cells were re-suspended, transferred to the Eppendorf tube at $4^{\circ} \mathrm{C}$ and centrifuged at $1,000 \mathrm{x}$ g for $5 \mathrm{~min}$. The supernatant was discarded again and $1 \mathrm{ml}$ PBS was added. The re-suspended cells were pre-cooled and fixed with $70 \%$ ethanol at $4^{\circ} \mathrm{C}$. The cells were centrifuged at $1,000 \mathrm{xg}$ for $5 \mathrm{~min}$ and the ethanol solution was discarded. Next, the cells were washed twice with PBS and filtered through a 400-mesh sieve, prior 

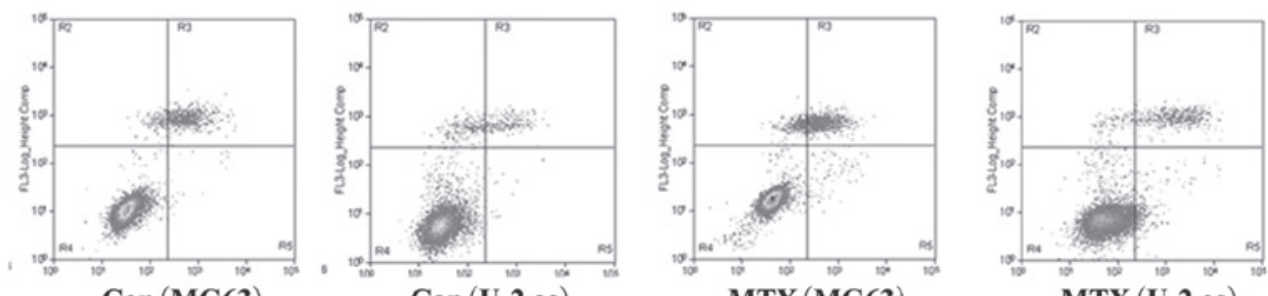

MTX(MG63)

$\operatorname{MTX}(\mathbf{U}-2$ os $)$
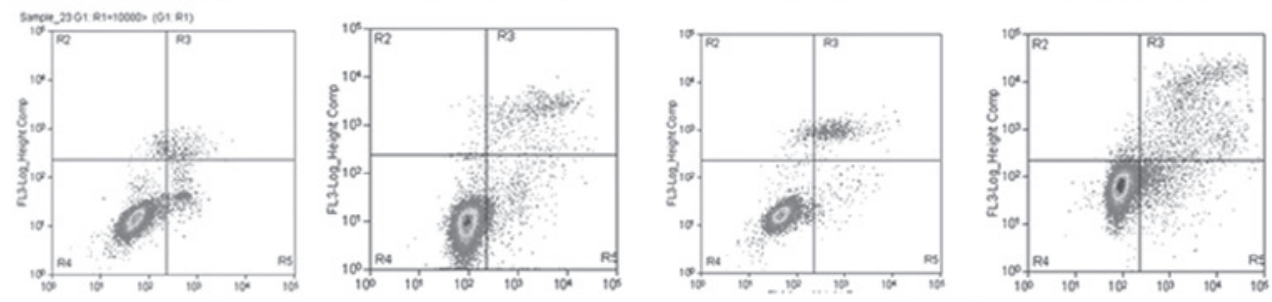

pre-miR-126 (MG63)
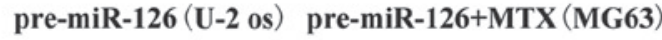

pre-miR-126+MTX (U-2 os)
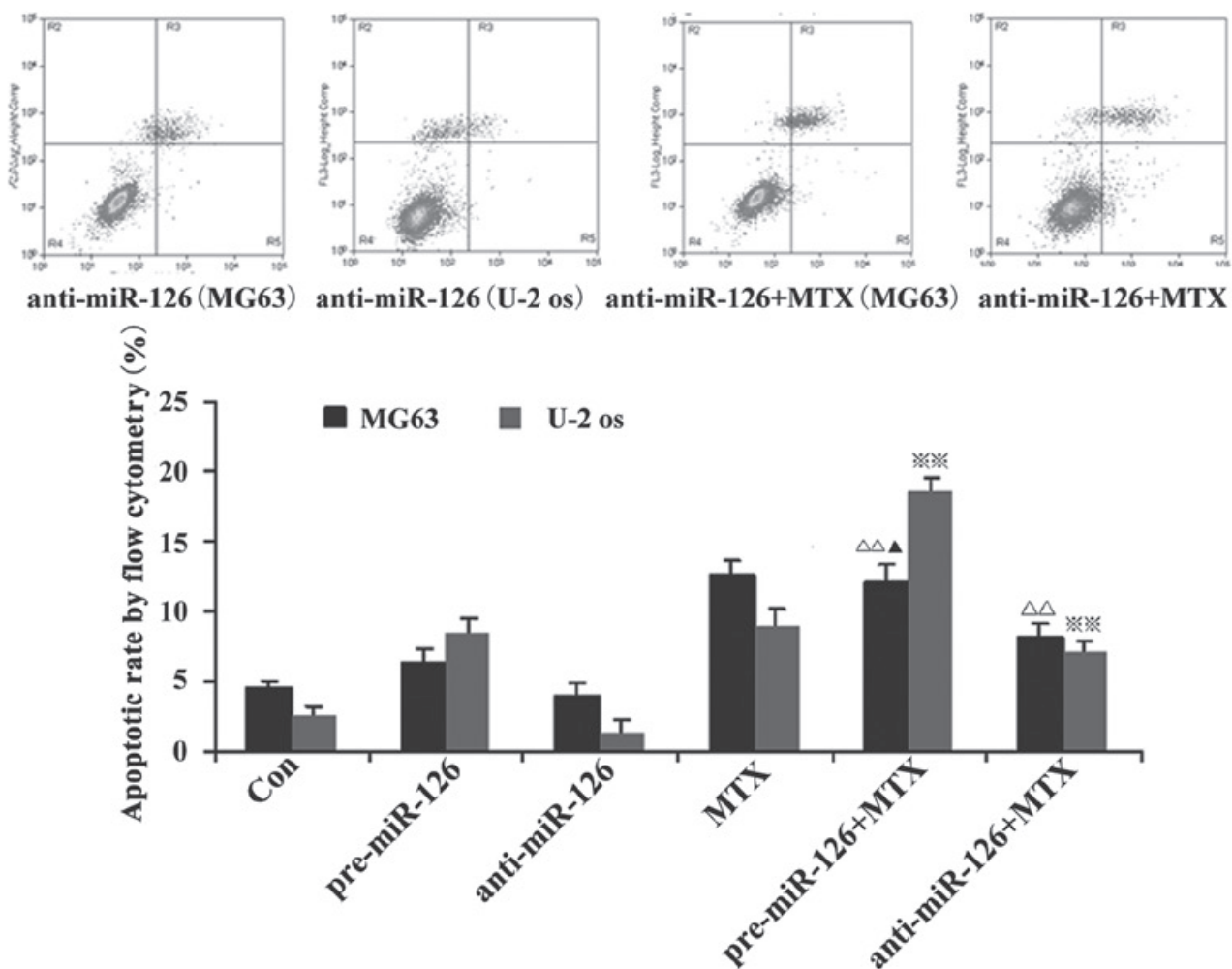

Figure 3. Effect of MTX on osteosarcoma cell apoptosis. Osteosarcoma cells (MG63 and U-2 OS) were infected with miR-126-overexpressing or -silencing lentiviral vectors. The effect of MTX on osteosarcoma cell apoptosis was then observed by flow cytometry. ${ }^{\Delta \Delta, * *} \mathrm{P}<0.01 \mathrm{vs}$. control group; ${ }^{\boldsymbol{\Lambda}} \mathrm{P}<0.05 \mathrm{vs}$. pre-miR-126 group. DDP, cisplatin; MTX, methotrexate; RAPA, rapamycin; pre-miR-126, osteosarcoma cells infected with miR-126-overexpressing lentiviral vectors; anti-miR-126, osteosarcoma cells infected with miR-126-silencing lentiviral vectors.

to propidium iodide dye being added at $4^{\circ} \mathrm{C}$ in darkness for staining for $30 \mathrm{~min}$. The proportion of cells in the $G_{0} / G_{1}$ phase, $\mathrm{S}$ phase and $\mathrm{G}_{2}$ phase was then detected by flow cytometry.

Statistical analysis. SPSS software, version 19.0 (SPSS, Inc., Chicago, IL, USA) were conducted for data analysis. Continuous data were presented with mean \pm standard deviation and examined with test of normality. Comparisons between two groups were conducted using Student's t-test and comparisons among multi groups were performed using homogeneity test of variance and one-way analysis of variance. Pairwise comparisons on mean values were determined using LSD t-test. $\mathrm{P}<0.05$ was considered to indicate a statistically significant difference.

\section{Results}

miR-126 overexpression is associated with the inhibitory effects of DDP and MTX upon the proliferation of osteosarcoma cells. The titer of miR-126-overexpressing and-silencing recombinant lentivirus was $1.07 \times 10^{9} \mathrm{U} / \mathrm{ml}$. Reverse transcription-PCR analysis showed that the miR-126 mRNA expression was increased in the stably-transected osteosarcoma cells overexpressing miR-126, while miR-126 mRNA expression was lowered in the osteosarcoma cells transfected with miR-126-silencing lentiviral vectors (data not shown).

The MTT assay showed that DDP and MTX exhibited inhibitory effects on the proliferation of the two osteosarcoma cell lines, 


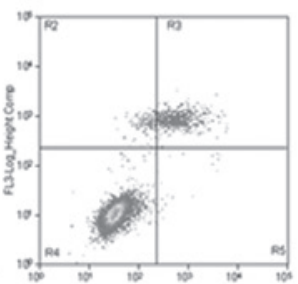

Con (MG63)

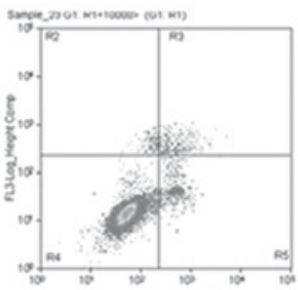

pre-miR-126 (MG63)

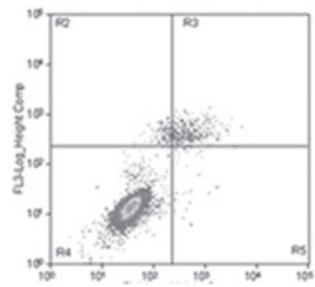

anti-miR-126 (MG63)

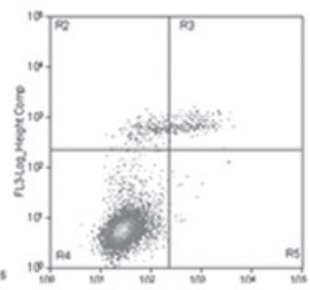

Con (U-2 os)
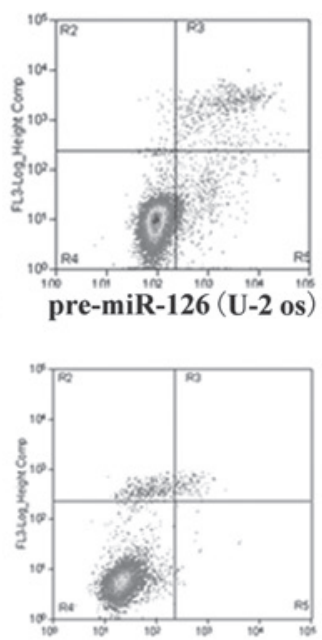

anti-miR-126 (U-2 os)

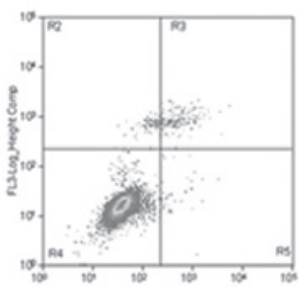

RAPA (MG63)

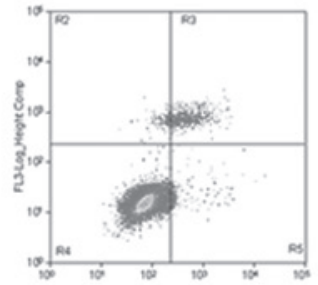

pre-miR-126+RAPA (MG63)

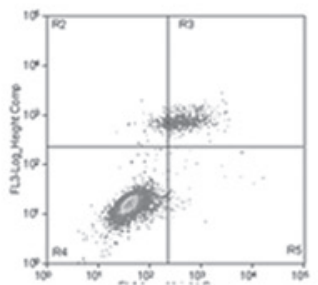

anti-miR-126+RAPA (MG63)

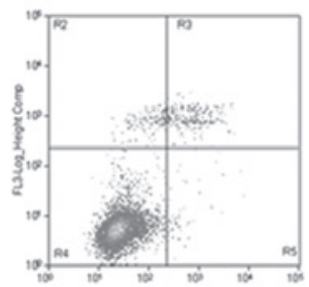

RAPA (U-2 os)

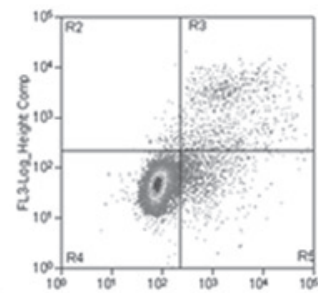

pre-miR-126+RAPA (U-2 os)

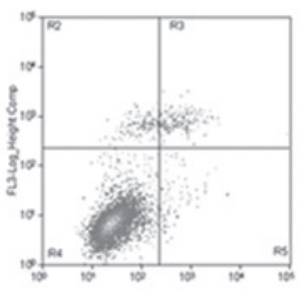

anti-miR-126+RAPA (U-2 os)

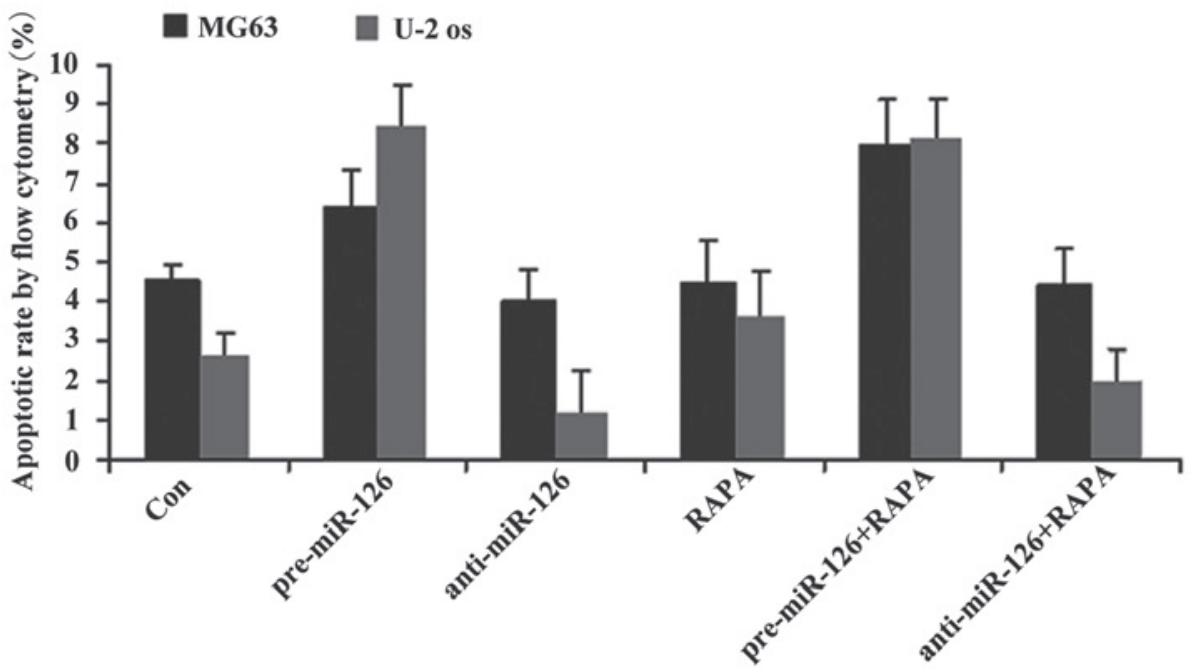

Figure 4. Effect of RAPA on osteosarcoma cell apoptosis. Osteosarcoma cells (MG63 and U-2 OS) were infected with miR-126-overexpressing or -silencing lentiviral vectors. The effect of RAPA on osteosarcoma cell apoptosis was then observed by flow cytometry. DDP, cisplatin; MTX, methotrexate; RAPA, rapamycin; pre-miR-126, osteosarcoma cells infected with miR-126-overexpressing lentiviral vectors; anti-miR-126, osteosarcoma cells infected with miR-126-silencing lentiviral vectors.

MG63 and U-2 OS (both $\mathrm{P}<0.05$ ), while RAPA, an inhibitor of the mammalian target of rapamycin (mTOR) signaling pathway, did not significantly inhibit cell proliferation compared with the control $(\mathrm{P}>0.05)$. During miR-126 overexpression, cell proliferation was observed to be weaker, whereas cell proliferation became stronger as the expression of miR-126 was lowered in the DDP-treated cells at the same concentration (Fig. 1A and B).

miR-126 overexpression is associated with the effects of DDP and MTX in the promotion of apoptosis in osteosarcoma cells. Flow cytometry showed that the apoptotic rate of the osteosarcoma cells increased with the overexpression of miR-126, while the silencing of miR-126 expression interfered with the apoptotic rate. When DDP or MTX were applied, the apoptotic rate of the osteosarcoma cells was significantly promoted by miR-126 overexpression (Figs. 2 and 3; both $\mathrm{P}<0.05$ ).

Although DDP or MTX have significant effects on the apoptotic rate in the miR-126-silenced osteosarcoma cells (both $\mathrm{P}<0.05)$, RAPA did not significantly promote the apoptosis of the osteosarcoma cells (Fig. 4; P>0.05).

miR-126 overexpression is associated with the inductive effects of DDP upon cycle of osteosarcoma cells. The flow cytometry suggested that there would be a decrease 

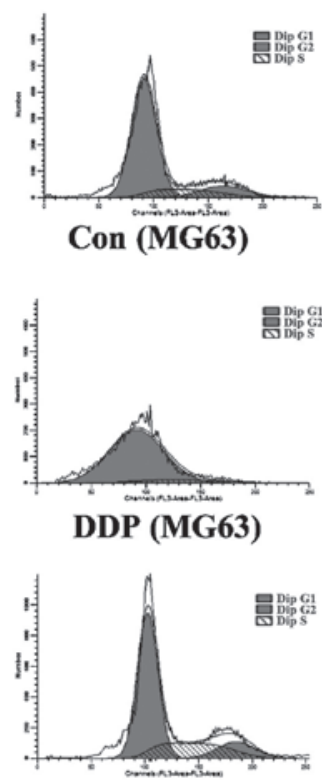

Con (U-2 os)

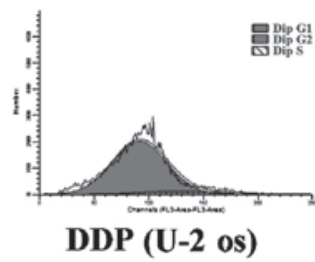

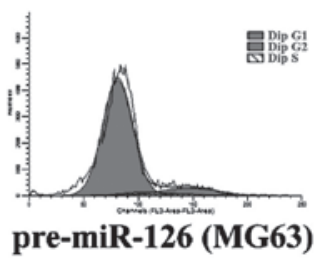

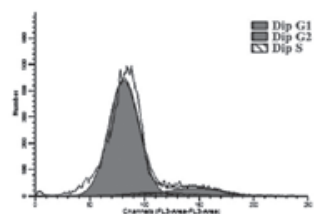

pre-miR-126+DDP (MG63)
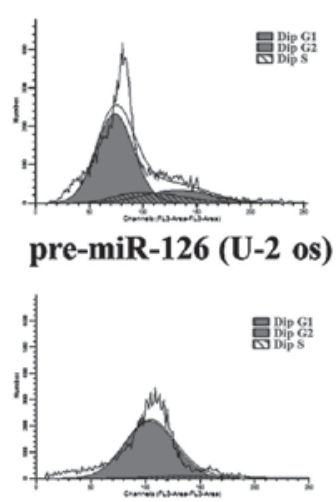

pre-miR-126+DDP (U-2 os)

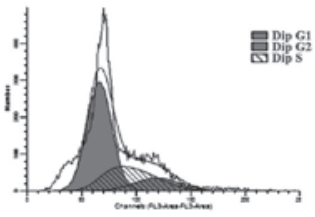

anti-miR-126 (MG63)

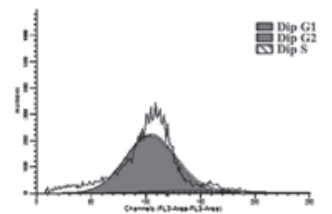

anti-miR-126+DDP (MG63)

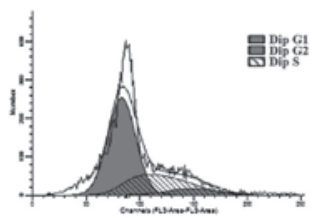

anti-miR-126 (U-2 os)

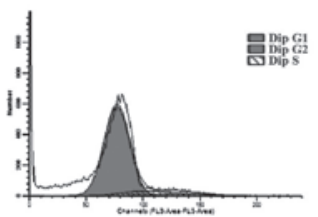

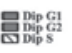

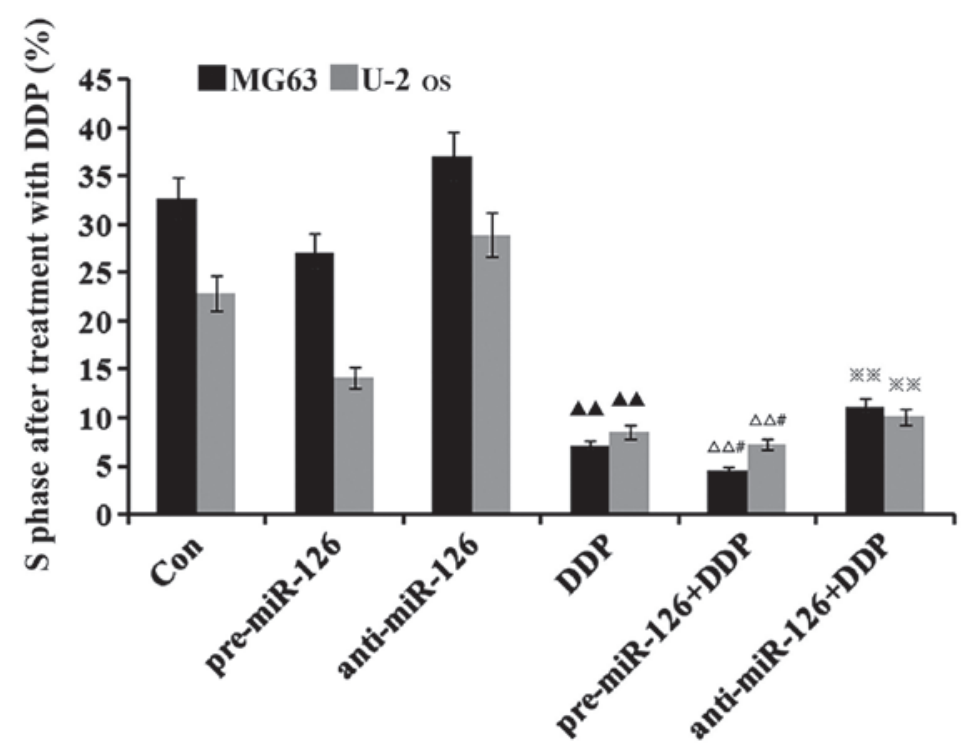

Figure 5. Effect of DDP on the cell cycle of osteosarcoma cells. Steosarcoma cells (MG63 and U-2-OS) were infected with miR-126-overexpressing or -silencing lentiviral vectors. The effect of DDP on the cell cycle of the osteosarcoma cells was observed by flow cytometry. Blank control, untreated MG63 and U-2-OS. DDP, cisplatin; MTX, methotrexate; RAPA, rapamycin; pre-miR-126, osteosarcoma cells infected with miR-126-overexpressing lentiviral vectors; anti-miR-126, osteosarcoma cells infected with miR-126-silencing lentiviral vectors. ${ }^{\boldsymbol{\Delta}} \mathrm{P}<0.01$ v.s. untreated control group; ${ }^{\Delta \Delta} \mathrm{P}<0.01$ v.s. pre-126 group; ${ }^{\#} \mathrm{P}<0.05$ v.s. DDP group; ${ }^{*} \mathrm{P}<0.05$ v.s. anti-126 group.

in the proportion of osteosarcoma cells in the $\mathrm{S}$ phase as DDP, MTX and RAPA were added to the osteosarcoma cells (Figs. 5-7). DDP had the best inhibitory effect (both $\mathrm{P}<0.05$ ), which was connected with changes in the miR-126 expression in the two osteosarcoma cell lines; the proportion of osteosarcoma cells in the $\mathrm{S}$ phase decreased with the increase of miR-126, while it increased as miR-126 was silenced (Fig. 5; both $\mathrm{P}<0.01$ ).

\section{Discussion}

As regulators of gene expression, miRNAs are involved in regulating multiple biological processes, including cell growth, apoptosis, tissue growth, tissue morphogenesis and the regulation of tumor growth (17-19). Highly expressed in human endothelial cells, miR-126 is closely associated with several types of cancer and is possibly one of the 

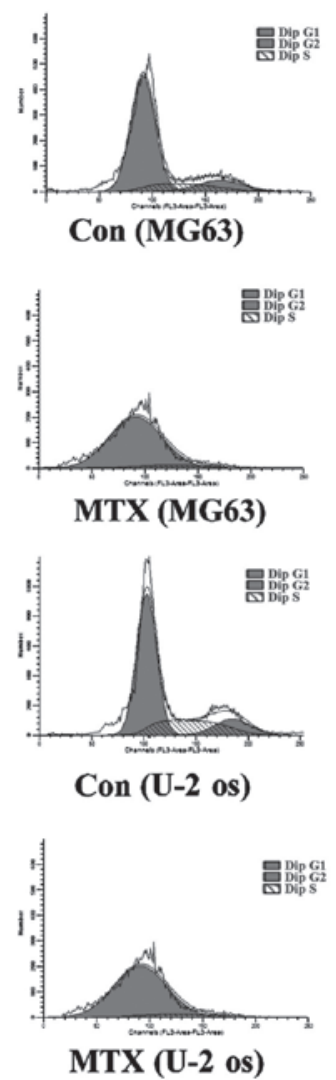
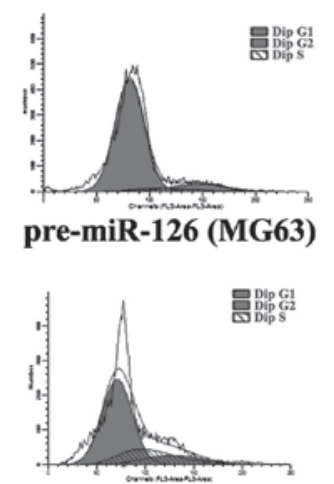

pre-miR-126+MTX (MG63)
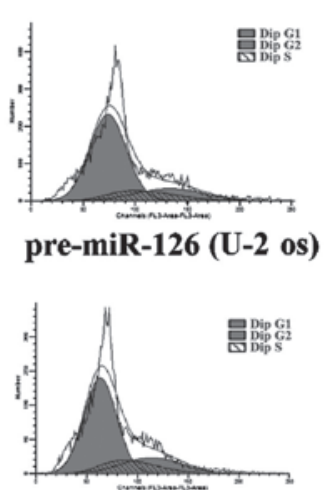

pre-miR-126+MTX (U-2 os)

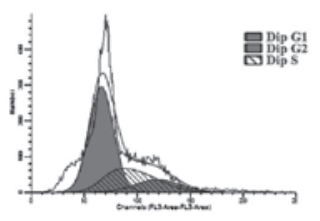

anti-miR-126 (MG63)

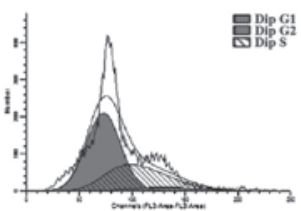

anti-miR-126+MTX (MG63)

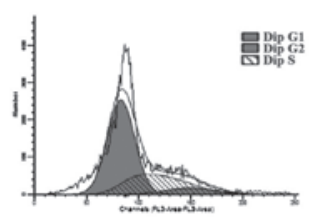

anti-miR-126 (U-2 os)

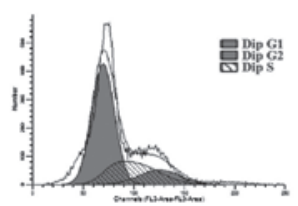

s) anti-miR-126+MTX (U-2 os)

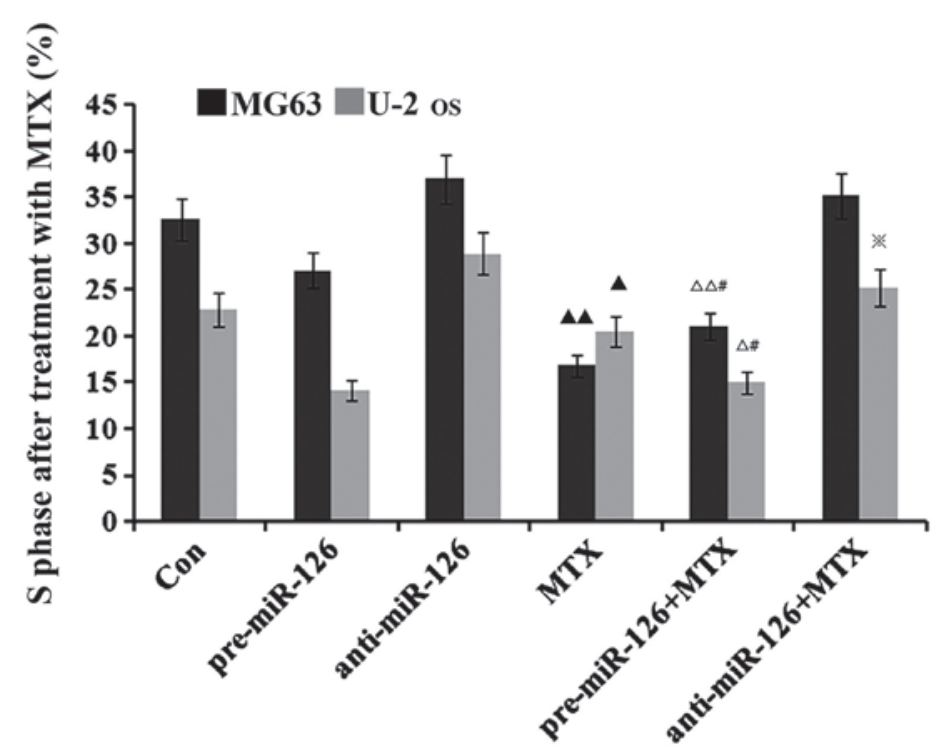

Figure 6. Effect of MTX on the cell cycle of osteosarcoma cells. Osteosarcoma cells (MG63 and U-2-OS) were infected with miR-126-overexpressing or -silencing lentiviral vectors. The effect of MTX on the cell cycle of the osteosarcoma cells was then observed by flow cytometry. Blank control, untreated MG63 and U-2-OS. DDP, cisplatin; MTX, methotrexate; RAPA, rapamycin; pre-miR-126, osteosarcoma cells infected with miR-126-overexpressing lentiviral vectors; anti-miR-126, osteosarcoma cells infected with miR-126-silencing lentiviral vectors. ${ }^{\Delta \mathbf{\Delta}} \mathrm{P}<0.01,{ }^{\mathbf{\Delta}} \mathrm{P}<0.05$, v.s. untreated control group; ${ }^{\Delta \Delta} \mathrm{P}<0.01$, ${ }^{\Delta} \mathrm{P}<0.05$ v.s. pre-126 group; ${ }^{\#} \mathrm{P}<0.05$ v.s. MTX group; ${ }^{*} \mathrm{P}<0.05$ v.s. anti-126 group.

future means for cancer treatment $(4,20)$. Each tumor has its specific miRNA expression profiles, so miRNAs may be utilized for the early diagnosis of tumors and for predicting prognosis $(21,22)$. The changes to the expression of miRNAs are closely connected with the formation and progression of human cancer. Current literature suggests that $\sim 50 \%$ of miRNAs are located within the genomic region associated with cancer, so miRNAs can be used as oncogenes or tumor suppressor genes.
Osteosarcoma is a progressive and fatal malignant bone tumor with a nearly unchanged case fatality rate (23). At present, the majority of studies advocate the comprehensive treatment of osteosarcoma, including the use of surgery, radiotherapy, chemotherapy and immune therapy (24-26). Chemotherapy was first used for the palliative treatment of advanced cases and achieved effects to a certain degree, thus promoting its application in the adjuvant treatment of early-stage patients to prevent metastasis. A previous study found that osteosarcoma 


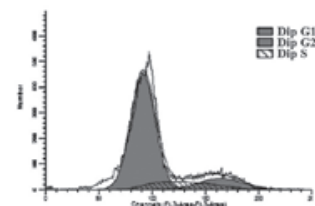

Con (MG63)

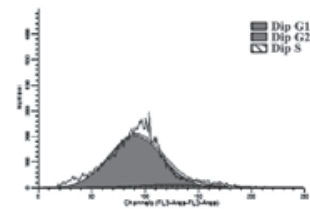

RAPA (MG63)

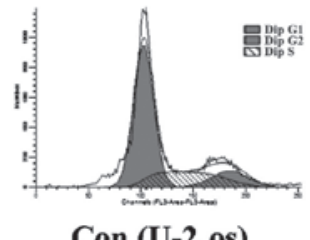

Con (U-2 os)

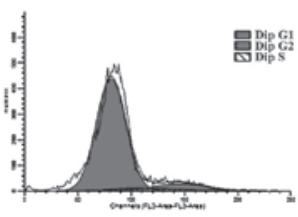

pre-miR-126 (MG63)

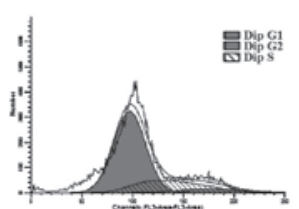

pre-miR-126+RAPA (MG63)
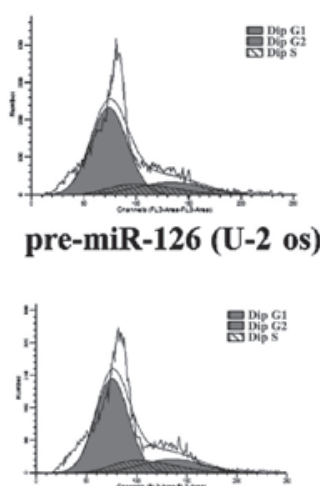

pre-miR-126+RAPA (U-2 os)

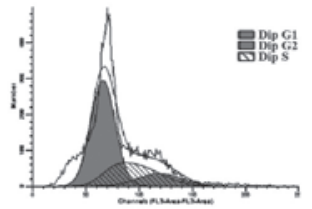

anti-miR-126 (MG63)

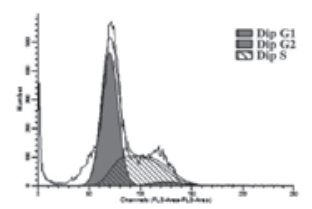

anti-miR-126+RAPA (MG63)

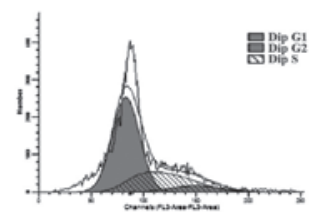

anti-miR-126 (U-2 os)

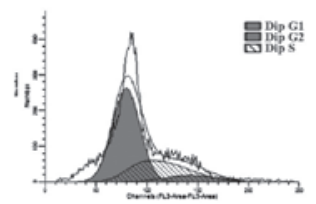

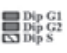
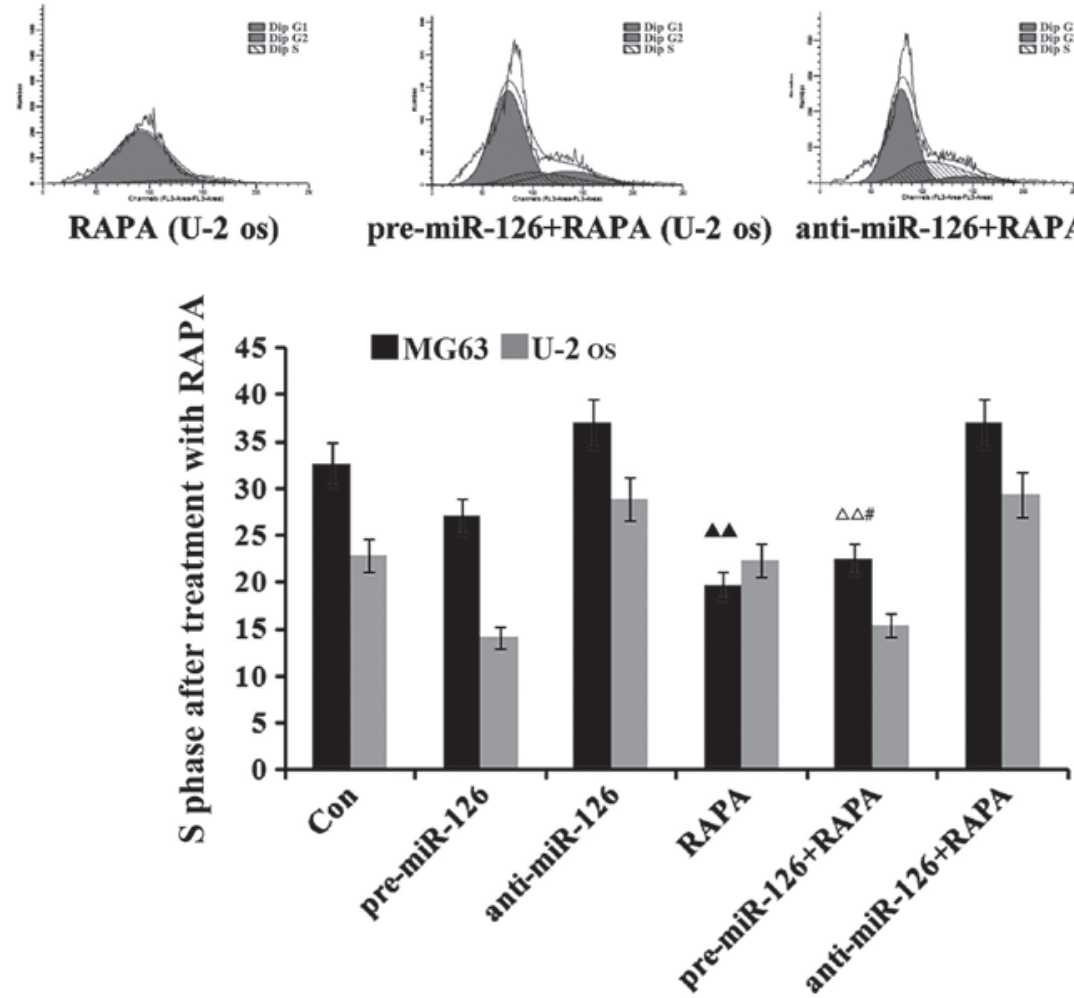

Figure 7. Effect of RAPA on the cell cycle of osteosarcoma cells. Osteosarcoma cells (MG63 and U-2-OS) were infected with miR-126-overexpressing or -silencing lentiviral vectors. The effect of RAPA on the cell cycle of the osteosarcoma cells was then observed by flow cytometry. Blank control, untreated MG63 and U-2-OS. DDP, cisplatin; MTX, methotrexate; RAPA, rapamycin; pre-miR-126, osteosarcoma cells infected with miR-126-overexpressing lentiviral vectors; anti-miR-126, osteosarcoma cells infected with miR-126-silencing lentiviral vectors. ${ }^{\Delta \Delta} \mathrm{P}<0.01$ v.s. untreated control group; ${ }^{\Delta \Delta} \mathrm{P}<0.01$ v.s. pre-126 group; ${ }^{\# P}<0.05$ v.s. RAPA group.

cells exhibited low level miR-126 expression and showed that the roles of this miRNA in osteosarcoma are not fully clear yet.

MTX has been primarily used for treating leukemia, choriocarcinoma, lung cancer, breast cancer and malignant lymphoma in the early stages $(27,28)$. Due to problems with drug resistance, its efficacy is somewhat limited when used at a conventional dose. Commonly used in the clinic as an anticancer drug, the relevant literature at home and abroad has reported that DDP has significant anti-tumor effects, is able to treat a variety of advanced cancers (including ovarian, breast and lung cancer) and can achieve ideal results in osteosarcoma cases when it is used together with MTX as a combination chemotherapy. In the present study, miR-126-overexpressing and -silencing lentiviral vectors were created to observe the impact of DDP and MTX on osteosarcoma cell proliferation, apoptosis and the cell cycle in two different osteosarcoma cell lines, MG63 and U-2 OS. 
The experimental results showed that DDP and MTX inhibited the proliferation of the two osteosarcoma cell lines with miR-126 overexpression. As a tumor suppressor gene, miR-126 may directly affect the sensitivity of cells to DDP through its expression. During the overexpression of miR-126, the proliferative ability of the osteosarcoma cells became weak, while the inhibitory effect upon cell proliferation when the miR-126 expression was lowered and the osteosarcoma cells were treated with DDP at the same concentration. This indicates that the level of miR-126 expression may not be associated with the inhibitory effect of DDP on the proliferation of osteosarcoma cells. In this study, it was observed that the apoptosis rate increased after miR-126 overexpression, but decreased after miR-126 expression was silenced. With the application of DDP and MTX, the apoptosis rate of the cells with miR-126 overexpression was significantly increased. It is therefore clear that miR-126 is associated with the apoptosis of osteosarcoma cells. Furthermore, DDP and MTX, as chemotherapy drugs, are involved in the regulation of this apoptosis of osteosarcoma cells through miR-126. Moreover, Zhang et al (29) demonstrated that cisplatin treatment could induce the knockdown of Akt2 expression to enhance the efficacy of chemotherapy in patients with osteosarcoma. Consistent with the results of the present study, a previous study showed that miR-126, as a tumor suppressor in osteosarcoma, whose ectopic expression inhibited invasion and induced apoptosis in osteosarcoma cells (30).

Flow cytometry suggested that the proportion of osteosarcoma cells in the $\mathrm{S}$ phase was reduced following the addition of DDP and MTX to the osteosarcoma cells. Furthermore, DDP exhibited the best inhibitory effects upon the cell cycle and was associated with the changes to the miR-126 expression level in the two osteosarcoma cell lines. This indicates that miR-126 is associated with the cell cycle of osteosarcoma cells and that DDP affects this cycle through miR-126, while the effects of chemotherapy may be enhanced when MTX is used together with DDP. To observe the signaling pathways through which miR-126 inhibits the proliferation and apoptosis of osteosarcoma cells, RAPA, an inhibitor of the mTOR pathway, was selected in this study. The results suggested that miR-126 may fail to give its roles into play in osteosarcoma cells via mTOR signals and its specific regulatory mechanisms remain to be further studied.

In summary, in the present study, DDP and MTX inhibited the proliferation of two osteosarcoma cell lines and promoted their apoptosis. Meanwhile, the effects of the drugs were dependent upon the high expression of miR-126 in the osteosarcoma cells. This further indicates that miR-126 may strengthen the sensitivity of osteosarcoma cells to DDP and MTX. This means that it is necessary to first detect the expression of miR-126 in patients when DDP and MTX are clinically used for treating osteosarcoma, so as to aid in increasing their sensitivity to the drugs and to improve the therapeutic effects.

\section{Acknowledgements}

This study was supported by the independent exploration and innovation project of Central South University Doctoral Students (grant no. 2013zzts096).

\section{References}

1. Chang SH and Hla T: Post-transcriptional gene regulation by $\mathrm{HuR}$ and microRNAs in angiogenesis. Curr Opin Hematol 21: 235-240, 2014.

2. Kane NM, Howard L, Descamps B, Meloni M, McClure J, Lu R, McCahill A, Breen C, Mackenzie RM, Delles C, et al: Role of microRNAs 99b, 181a and 181b in the differentiation of human embryonic stem cells to vascular endothelial cells. Stem Cells 30: 643-654, 2012.

3. Mishra RR, Kneitz S and Schartl M: Comparative analysis of melanoma deregulated miRNAs in the medaka and Xiphophorus pigment cell cancer models. Comp Biochem Physiol C Toxicol Pharmacol 163: 64-76, 2014.

4. Xu JQ, Liu P, Si MJ and Ding XY: MicroRNA-126 inhibits osteosarcoma cells proliferation by targeting Sirt1. Tumour Biol 34: 3871-3877, 2013.

5. Bago-Horvath Z, Schmid K, Rössler F, Nagy-Bojarszky K, Funovics P and Sulzbacher I: Impact of RANK signalling on survival and chemotherapy response in osteosarcoma. Pathology 46: 411-415, 2014.

6. Guma SR, Lee DA, Ling Y, Gordon N and Kleinerman ES: Aerosol interleukin-2 induces natural killer cell proliferation in the lung and combination therapy improves the survival of mice with osteosarcoma lung metastasis. Pediatr Blood Cancer 61: 1362-1368, 2014.

7. Ohba T, Cole HA, Cates JM, Slosky DA, Haro H, Ando T, Schwartz HS and Schoenecker JG: Bisphosphonates inhibit osteosarcoma-mediated osteolysis via attenuation of tumor expression of MCP-1 and RANKL. J Bone Miner Res 29: 1431-1445, 2014.

8. Rabinowicz R, Barchana M, Liphshiz I, Futerman B, Linn S and Weyl-Ben-Arush M: Cancer incidence and survival among children and adolescents in Israel during the years 1998 to 2007. J Pediatr Hematol Oncol 34: 421-429, 2012.

9. Salas S1, Jiguet-Jiglaire C, Campion L, Bartoli C, Frassineti F, Deville JL, Maues De Paula A, Forest F, Jézéquel P, Gentet JC and Bouvier C: Correlation between ERK1 and STAT3 expression and chemoresistance in patients with conventional osteosarcoma. BMC Cancer 14: 606, 2014.

10. Ottaviani G and Jaffe N: The epidemiology of osteosarcoma. Cancer Treat Res 152: 3-13, 2009.

11. Valle J, Wasan H, Palmer DH, Cunningham D, Anthoney A, Maraveyas A, Madhusudan S, Iveson T, Hughes S, Pereira SP, et al; ABC-02 Trial Investigators: Cisplatin plus gemcitabine versus gemcitabine for biliary tract cancer. N Engl J Med 362: 1273-1281, 2010.

12. Westlake SL1, Colebatch AN, Baird J, Kiely P, Quinn M, Choy E, Ostor AJ and Edwards CJ: The effect of methotrexate on cardiovascular disease in patients with rheumatoid arthritis: a systematic literature review. Rheumatology (Oxford) 49: 295-307, 2010.

13. Lin F, Wang Q, Yu W, Tang L, Zheng S, Sun Y, Shen Z, Yao Y and Dong Y: Clinical analysis of Chinese limb osteosarcoma patients treated by two combinations of methotrexate, cisplatin, doxorubicin and ifosfamide. Asia Pac J Clin Oncol 7: 270-275, 2011.

14. Yang TM, Qi SN, Zhao N, Yang YJ, Yuan HQ, Zhang B and Jin S: Induction of apoptosis through caspase-independent or caspase-9-dependent pathway in mouse and human osteosarcoma cells by a new nitroxyl spin-labeled derivative of podophyllotoxin. Apoptosis 18: 727-738, 2013.

15. Ghayad SE and Cohen PA: Inhibitors of the PI3K/Akt/mTOR pathway: new hope for breast cancer patients. Recent Pat Anticancer Drug Discov 5: 29-57, 2010.

16. Markman B, Dienstmann R and Tabernero J: Targeting the $\mathrm{PI} 3 \mathrm{~K} / \mathrm{Akt} / \mathrm{mTOR}$ pathway - beyond rapalogs. Oncotarget 1: 530-543, 2010.

17. Gits CM, van Kuijk PF, Jonkers MB, Boersma AW, Smid M, van Ijcken WF, Coindre JM, Chibon F, Verhoef C, Mathijssen RH, et al: MicroRNA expression profiles distinguish liposarcoma subtypes and implicate miR-145 and miR-451 as tumor suppressors. Int J Cancer 135: 348-361, 2014.

18. Guled M, Pazzaglia L, Borze I, Mosakhani N, Novello C, Benassi MS and Knuutila S: Differentiating soft tissue leiomyosarcoma and undifferentiated pleomorphic sarcoma: A miRNA analysis. Genes Chromosomes Cancer 53: 693-702, 2014.

19. Tafra R, Brakus SM, Vukojevic K, Kablar B, Colovic Z and Saraga-Babic M: Interplay of proliferation and proapoptotic and antiapoptotic factors is revealed in the early human inner ear development. Otol Neurotol 35: 695-703, 2014. 
20. Liu Y, Zhou Y, Feng X, Yang P, Yang J, An P, Wang H, Ye S, $\mathrm{Yu} \mathrm{C}, \mathrm{He} \mathrm{Y}$ and Luo $\mathrm{H}$ : Low expression of microRNA-126 is associated with poor prognosis in colorectal cancer. Genes Chromosomes Cancer 53: 358-365, 2014

21. Rabinowits G, Gercel-Taylor C, Day JM, Taylor DD and Kloecker GH: Exosomal microRNA: A diagnostic marker for lung cancer. Clin Lung Cancer 10: 42-46, 2009.

22. Schaefer A, Jung M, Mollenkopf HJ, Wagner I, Stephan C, Jentzmik F, Miller K, Lein M, Kristiansen G and Jung K: Diagnostic and prognostic implications of microRNA profiling in prostate carcinoma. Int J Cancer 126: 1166-1176, 2010.

23. Guma SR, Lee DA, Yu L, Gordon N, Hughes D, Stewart J, Wang WL and Kleinerman ES: Natural killer cell therapy and aerosol interleukin-2 for the treatment of osteosarcoma lung metastasis. Pediatr Blood Cancer 61: 618-626, 2014.

24. Anninga JK, Gelderblom H, Fiocco M,Kroep JR, Taminiau AH, Hogendoorn PC and Egeler RM: Chemotherapeutic adjuvant treatment for osteosarcoma: Where do we stand? Eur J Cancer 47: 2431-2445, 2011

25. Rainusso N, Brawley VS, Ghazi A, Gottschalk S, Rosen JM and Ahmed N: Immunotherapy targeting HER2 with genetically modified T-cells eliminates tumor-initiating cells in osteosarcoma. Cancer Gene Ther 19: 212-217, 2012.
26. Ando K, Heymann MF, Stresing V, Mori K, Rédini F and Heymann D: Current therapeutic strategies and novel approaches in osteosarcoma. Cancers (Basel) 5: 591-616, 2013.

27. Luckasson R and Schalock RL: What's at stake in the lives of people with intellectual disability? Part II: Recommendations for naming, defining, diagnosing, classifying and planning supports. Intellect Dev Disabil 51: 94-101, 2013.

28. Moritake H, Kamimura S, Kojima H, Shimonodan H, Harada M, Sugimoto T, Nao-I N and Nunoi H: Cytomegalovirus retinitis as an adverse immunological effect of pulses of vincristine and dexamethasone in maintenance therapy for childhood acute lymphoblastic leukemia. Pediatr Blood Cancer 60: 329-331, 2013.

29. Zhang G, Li M, Zhu X and Yang C: Knockdown of Akt sensitizes osteosarcoma cells to apoptosis induced by cisplatin treatment. Int J Mol Sci 12: 2994-3005, 2011.

30. Ell B and Kang Y: MicroRNAs as regulators of bone homeostasis and bone metastasis. Bonekey Rep 3: 549, 2014. 